\title{
Assessing climate risks to UK agriculture
}

To the Editor - In January 2012, the first Climate Change Risk Assessment (CCRA) report was presented to the UK government to inform national adaptation policy. Regarding the agricultural sector, we and our colleagues used a risk-metric approach to assess consequences for crop yield ${ }^{1}$. Writing in Nature Climate Change, Semenov et al. ${ }^{2}$ present a critique on the crop yield metric used in our analysis. Although we do not refute the scientific evidence presented, we do question its purpose. It is important to explain here the context of the CCRA agriculture sector research, the intended purpose of the risk metric on wheat yield, and how the findings are to be used by government. There are important messages too on how climate change evidence can be misinterpreted.

The critique ${ }^{2}$ focuses on the validity of an analysis that linked changes in temperature to changes in wheat yield. The CCRA used a linear regression to relate the UK national average annual wheat yield (1960-2007) to UK mean temperature (March to November). The rationale for using a single climate variable and national data sets was to build a consistent picture of risk and allow for some comparison between disparate risks and national differences across CCRA sectors $^{3}$. For wheat (and other crops studied), the crop yield risk-metric outputs should not be interpreted as predictions of future yield change. They were projections to illustrate and allow comparison of potential risks and opportunities from climate change. The point is subtle, but extremely important, and made explicitly clear throughout all CCRA reports ${ }^{1,3}$. The approach was also intended to be tractable, repeatable and not dependent on changes in long-term plans between the five-year cycles of the CCRA.

For wheat, the analysis provided a broad-scale measure of the effect of temperature (using the latest UK climate projections ${ }^{4}$ ) on crop yield and suggested that warmer summers may, on their own, provide a positive effect. However, this was not a prediction of yield change, as no other factors were taken into account. For example, future changes due to plant breeding and disease control, the combined effects of other climate variables (for example, rainfall) on crop development, changes in atmospheric carbon dioxide concentration, agricultural practices and future agricultural economic policy on yield were all excluded. This was explicit ${ }^{1}$, with government assurance that it did not view any of the results in this light, as that would be an incorrect interpretation of the analysis.

\section{This experience has shown that the way messages are communicated and interpreted is critical.}

Significant effort was made to ensure that the results were not taken out of context, both in the agriculture sector report ${ }^{1}$ and the evidence report ${ }^{3}$. Indeed for wheat, the agriculture sector report clearly stated: "The [wheat] metric developed is thus considered too crude for any objective assessment of the future impact of climate change on yield, but highlights the limitation of using a single climate variable and national statistics for impact assessment."

Alternative climate impact evidence was provided to support discussion of and conclusions from the analysis, drawing on recent biophysical modelling studies for wheat ${ }^{5}$, potatoes ${ }^{6}$ and sugar beet ${ }^{7}$, the other reference crops included in the CCRA.

Given the significance of the CCRA to climate change policy and decisionmaking, the outputs were extensively peer-reviewed, using standard government procedures as well as incorporating feedback from a range of stakeholders. For agriculture, three scientists with leading international expertise in climate change impacts on crop production and livestock were appointed and their comments addressed as far as was practically and pragmatically feasible. The evidence report $\mathrm{t}^{3}$ was also peer-reviewed by an international panel of experts chaired by a leading UK climate change scientist. Comments from both the peer-review and the panel were that the intended use and limitations of the metric analysis needed to be made explicit. Further clarification was thus included ${ }^{1,3}$.

Finally, it is important to stress that the government intends to use the CCRA agriculture outputs alongside other evidence, including multivariate research and international expertise (for example, ref. 8). This will be used to support a National Adaptation Programme recognizing that climate risks are only part of the overall challenge; the economics of climate resilience and the sensitivity of sectors such as agriculture to a raft of other externalities or 'non-climate' risks" will also need to be considered. This process too will inevitably create widespread debate within and beyond the scientific community. This experience has shown that the way messages are communicated and interpreted is critical, and that scientists, like the media, can also sometimes be guilty of taking an interest in only part of the overall message.

References

1. Knox, J. W., Hurford, A., Hargreaves, L. \& Wall, E. Climate Change Risk Assessment for the Agriculture Sector (Defra, 2012).

2. Semenov, M. A. et al. Nature Clim. Change 2, 380-382 (2012).

3. CCRA The UK Climate Change Risk Assessment 201: Evidence Report (Defra, 2012).

4. Jenkins, G. J. et al. UK Climate Projections: Briefing Report (UK Met Office Hadley Centre, 2009).

5. Semenov, M. J. R. Soc. Interface 6, 343-350 (2009).

6. Daccache, A., Weatherhead, E. K., Stalham, M. A. \& Knox, J. W. Agr. Forest Meteorol. 151, 1641-1653 (2011).

7. Richter, G. M., Qi, A., Semenov, M. A. \& Jaggard, K. W. Soil Use Manage. 22, 39-47 (2006).

8. Nelson, G. C. et al. Food Security, Farming, and Climate Change to 2050: Scenarios, Results, Policy Options (International Food Policy Research Institute, 2010).

9. Knox, J. W., Morris, J. \& Hess, T. M. Outlook Agr. 39, 249-256 (2010).

Jerry W. Knox ${ }^{1 \star}$ and Steven Wade ${ }^{2}$

${ }^{1}$ Cranfield Water Science Institute, Cranfield

University, Bedford MK43 OAL, UK, ${ }^{2} \mathrm{HR}$

Wallingford, Howbery Park, Wallingford,

Oxfordshire OX10 8BA, UK

*e-mail: j.knox@cranfield.ac.uk 